\title{
JUSTIÇA ESCOLAR E JUSTIÇA DIFERENCIALISTA NOS DOCUMENTOS ADOTADOS POR ÓRGÃOS DAS NAÇÕES UNIDAS (PNUD E UNESCO)
}

\author{
Maria José de Rezende \\ é professora associada do Departamento de Ciências Sociais da Universidade
}

Estadual de Londrina (UEL)

Londrina, PR, Brasil.E-mail: mjderezende@gmail.com

Orcid: 0000-0002-3426-910X

http://dx.doi.org/10.1590/0102-121135/108

\section{Introdução}

Não são objetos desta investigação aquelas prescrições de políticas educacionais e pedagógicas não assentadas em perspectivas de direitos tais como os baseados em modelos mentais. O foco está nas orientações ancoradas nas abordagens das capacidades que estão contidas nas propostas da Educação para Todos, as quais estão presentes nos Relatórios do Desenvolvimento Humano (RDH) encomendados pelo Programa das Nações Unidas para o Desenvolvimento (PNUD) ${ }^{1}$ e nos Relatórios de Monitoramento Global das Metas Educação para Todos (REPT) encomendados pela Organização das Nações Unidas para a Educação, a Ciência e a Cultura (Unesco). ${ }^{2}$ Ambas são norteadas por propostas educacionais alicerçadas na ideia de que o saber, o conhecimento e o desenvolvimento social fazem parte dos direitos fundamentais e humanos. A justiça escolar faz-se quando se incorporam os

\footnotetext{
1 Os RDH são produzidos e divulgados anualmente, desde 1990.

2 Os REPT são divulgados pela Unesco desde 2002.
} 
mais pobres e os grupos discriminados, pelas mais diversas razões, em um processo de escolarização que os capacite e habilite a participar das contendas econômicas e políticas.

Não serão analisados os modelos educacionais centrados na expansão da cognição, segundo os moldes discutidos pelas ciências comportamentais e pela neurociência, os quais têm encontrado guarida no âmbito dos diagnósticos e prognósticos feitos para a área educacional nos Relatórios do Desenvolvimento do Banco Mundial. Pode-se dizer que o modelo cognitivo adotado pelo Banco Mundial estabelece-se como um marco de afastamento do amplo leque de debates (Dionísio, 2010; Dubet, 2004, 2012; Estevão, 2002; 2016; Resende e Dionísio, 2005) que têm alinhavado a noção de escola justa ancorada numa perspectiva de direitos.

Em 2015 o Banco Mundial divulgou uma publicação intitulada Mente, sociedad y conducta, na qual está condensado um modelo de educação que, conforme destaca Horácio 122 Javier Etchichury (2015), se desvia de uma perspectiva de direito humanos e assenta-se na busca de uma educação capaz de modificar os modelos mentais e os processos de tomada de decisão. Assim, trata-se de uma educação norteada pela mudança cognitiva dos indivíduos. ${ }^{3}$ Se eles não saem da pobreza, o problema são seus modelos mentais, que orientam para decisões equivocadas ao longo de sua vida. Não se trata de injustiça social ou escolar, mas de escolhas equivocadas assentadas em modelos mentais que a educação deve modificar (Etchichury, 2015). De modo diferente,

A perspectiva dos direitos ajuda a transferir a prioridade para os mais pobres e excluídos, especialmente para privações devidas à discriminação. Também canaliza

\footnotetext{
${ }^{3}$ Pode-se dizer que esse modelo educativo tem proximidade com aquele denominado de formador do capital humano, o qual "valoriza, em síntese, um enquadramento mais empresarialista e mercantilista da educação, que, nos dias de hoje, tende, como vimos, a ser dominante" (Estevão, 2016, p. 44).
} 
a atenção para a necessidade de informação e de voz política para todas as pessoas, como uma questão de desenvolvimento - e para os direitos civis e políticos, como partes integrantes do processo de desenvolvimento. (PNUD/RDH, 2000a, p. 3)

\section{Justiça escolar e justiça diferencialista: como elas aparecem nos RDH e nos REPT?}

Carlos Estevão (2016) destaca que uma escola justa se faz também no seu cotidiano, através de ações e de procedimentos que indiquem o quanto todos os que circundam o universo escolar estão se esforçando para dar aos estudantes a certeza de que todos são iguais e assim serão tratados em todas as dimensões da vida escolar. Isso, porém, não pode levar à desconsideração das dificuldades de aprendizado e de sociabilidade que, por muitas razões, afetam mais a uns do que a outros. Assim, elementos universais e diferencialistas devem ser contemplados quando se fala de justiça escolar e de escola justa.

Uma escola justa e de qualidade deve mobilizar a justiça escolar como igualdade de tratamento, quer no acesso, quer no sucesso, quer na possibilidade de permanecer no sistema [...], mas também a justiça diferencialista, dando mais aos que mais necessitam, designadamente aos que revelem dificuldades ou necessidades educativas especiais. Estes terão eventualmente de usufruir de políticas compensatórias, no sentido de os tornar mais capazes de realizar o que de facto valorizam [...]. (Estevão, 2016, pp. 53-54)

Tendo como base as indicações de Luc Boltanski sobre competência reflexiva (2009), pode-se dizer que a escola justa seria aquela em que todos os membros desenvolvem habilidades para lidar com situações problemáticas, tanto dentro quanto fora do espaço escolar. Pode-se intuir, então, 
que a justiça escolar levaria ao desenvolvimento da cooperação. Os indivíduos seriam formados para lidar, de modo cooperativo e integrador, com as situações mais difíceis (Campos, 2016). Boltanski e Thévenot (1991, 1999) afirmam, segundo Campos (2016, p. 724), que “[...] as controvérsias públicas, são resolvidas a partir de complexas operações de construção de equivalências e atribuições de grandezas". Este artigo não discutirá, ainda que se considere isto fundamental, como a perspectiva de Boltanski se inscreve num situacionismo metodológico (Celikates, 2012) que se afasta da

possibilidade de trabalhar com as controvérsias ou os problemas públicos de longa duração. Trata-se de problemas coletivos duráveis, cuja temporalidade se estende por anos e décadas, e cujo modo de encerramento não é apenas, a princípio, indeterminado, como também não tem o seu modo de encerramento dado pela referência a um princípio moral de caráter universalista. (Corrêa e Dias, 2016, pp. 89-90)

A perspectiva pragmática de Boltanski e Thévenot (1991), firmada na "capacidade que os indivíduos têm em julgar reflexivamente a realidade social" (Campos, 2016, p. 720), ajuda na leitura acerca de como os REPT e RDH apostam na escolarização como forma de construir indivíduos que se capacitem sempre mais a participar da vida social. Embora muitas pessoas estejam em situação de enorme desvantagem social, a educação é mostrada pelos elaboradores desses documentos como parte do processo capacitador e habilitador. Nos documentos encampados por órgãos das Nações Unidas (PNUD e Unesco), os sujeitos sociais aparecem como dotados de potencialidade para entender e mudar a realidade na qual estão inseridos. Pessoas extremamente pobres, discriminadas por razões diversas e oriundas dos lugares mais remotos da Terra são tidas nesses materiais 
como capazes de se habilitarem para sair da situação de pobreza extrema.

Isso não quer dizer que tal capacidade seja uma "potencialidade onipresente nas relações sociais", como aparece em Boltanski (Campos, 2016, p. 720). Baseados em Sen $(2010,2011)$, os formuladores dos RDH pressupõem que as capacidades e habilidades são "socialmente adquiridas" (Campos, 2016, p. 720). Daí a afirmação de que um dos eixos do desenvolvimento humano é a educação geradora efetiva de igualdade de capacidades, por meio das "várias combinações de funcionamentos (estados e ações) que uma pessoa pode realizar. A capacidade é, portanto, um conjunto de vetores de funcionamentos" (Sen, 2008, p. 80).

A ideia de inadequação de capacidades de Sen indica seu distanciamento de alguns pressupostos de Boltanski. Todavia, os dois possuem pontos de convergência quando creditam às pessoas uma expressiva capacidade de refletir sobre o mundo social no qual estão inseridas. Enquanto para Boltanski "os seres sociais [...] são seres, essencialmente, dotados de avançadas competências reflexivas" (Campos, 2016, p. 720), para Sen tais competências têm de ser construídas.

Para Celikates (2012), Boltanski

[...] não parece levar em conta as condições sociais do exercício ou da formação das capacidades reflexivas e críticas que pressupõe. A sociologia da crítica ${ }^{4}$ não nega, é claro, que os atores adquiram e exercitem suas capacidades no interior de contextos sociais existentes e, portanto, sempre sob determinadas condições sociais $[\ldots]$.

[No entanto,] devido [...] a sua orientação "situacionista", essa abordagem tende a considerar esses contextos e condições

${ }^{4}$ A perspectiva de Boltanski é denominada sociologia da crítica como forma de se
distinguir da sociologia crítica de Pierre Bourdieu. Ver Boltanski e Thévenot (1999). 
como meros recursos que os atores podem mobilizar, e não como potenciais restrições estruturais as suas capacidades reflexivas e práticas críticas. (Celikates, 2012, p. 38)

\section{Geração e expansão da justiça escolar e da justiça diferencialista: aspectos macrossociais e microssociais}

Por falar em contextos sociais bloqueadores das possibilidades de fazer frutificar a justiça escolar e a justiça diferencialista, os formuladores dos REPT, ao se dedicarem aos aspectos microssociais e macrossociais que implodem as metas Educação para Todos, fornecem elementos importantes para a análise empreendida neste artigo, a respeito de como os organismos internacionais têm participado tanto na construção quanto num certo enquadramento analítico do debate sobre escola justa. Enquanto os REPT se dedicam mais aos impedimentos e bloqueios vindos da marginalização, ${ }^{5}$ das guerras, dos conflitos, das discriminações, dos preconceitos e da violência que acometem as crianças na família, no bairro e na cidade onde vivem, os $\mathrm{RDH}$ apresentam reflexões mais genéricas sobre os eixos norteadores do desenvolvimento humano e constroem vários desvios das situações microssociais e seus contextos sociais, culturais, econômicos e políticos que funcionam como travas à constituição de capacidades e habilidades.

Fica evidente que os construtores dos REPT e dos RDH se dedicam inteiramente não só a diagnosticar os recursos disponíveis - dentro dos contextos dificílimos em que vivem os mais excluídos (por motivos econômicos, culturais, sociais, religiosos, raciais, étnicos) - aos que estão em situação de privação e de impotência, mas também a prescrever e empreender ações e procedimentos sinérgicos a fim de

\footnotetext{
${ }^{5}$ Os formuladores dos REPT utilizam com muita frequência a noção de marginalização para ressaltar os muitos processos de exclusão social.
} 
produzir o desenvolvimento humano capaz de ampliar as condições de acesso à renda, à educação, à moradia adequada, à liberdade e ao respeito.

Os direitos humanos e o desenvolvimento humano tratam ambos da garantia das liberdades básicas. Os direitos humanos exprimem a ideia ousada de que todas as pessoas têm direito aos arranjos sociais que as protegem dos piores abusos e privações - e que asseguram a liberdade de uma vida digna. O desenvolvimento humano, por seu turno, é um processo que melhora as capacidades humanas - alarga as escolhas e oportunidades, de forma que cada pessoa possa levar uma vida de respeito e valor. (PNUD/RDH, 2000a, p. 2)

A Declaração mundial sobre educação para todos ${ }^{6}$ (Conferência Mundial..., 1990) já no $1^{\circ}$ artigo ressaltava que os conteúdos escolares deveriam se sustentar no respeito pelos hábitos, costumes, língua, religião e valores dos mais diversos grupos étnico-raciais. Tanto os REPT como os RDH destacam, no processo de escolarização, a igualdade de tratamento a todos os estudantes, das mais diversas condições e grupos sociais. Todavia, o RDH de 2004 é o que mais se dedica a esse tema, com o subtítulo A liberdade cultural no mundo hoje (PNUD/RDH, 2004).

Nestes dois grupos diversos de documentos há um diálogo com os eixos constituidores da ideia de escola justa e justiça escolar, defendendo que os mais pobres, os discriminados e pertencentes aos grupos étnico-raciais que sofrem por não ser reconhecidos como pessoas e sujeitos de direitos sejam tratados de forma igual, não só no acesso à escola como também na vivência escolar. Isso só poderá

\footnotetext{
${ }^{6}$ As metas são: expandir o acesso à educação de crianças entre 3 e 6 anos; universalizar o ensino primário e ampliar a possibilidade de os jovens acessarem o conhecimento; tornar a educação básica de meninos e meninas equitativa; melhorar a qualidade educacional; ampliar a educação de adultos (Fórum Mundial de Educação, 2000).
} 
ser feito se for construído um ambiente de respeito a culturas e valores diversos. Ressalte-se que as condições de pobreza, miserabilidade e exclusão são bastante enfatizadas nos documentos do PNUD e da Unesco aqui tratados como fontes de estudo. Consta no RDH de 2003 que “as respostas políticas aos constrangimentos estruturais exigem intervenções simultâneas em várias frentes [...]. Investir cedo e ambiciosamente na educação básica e na saúde, estimulando ao mesmo tempo a igualdade de gênero" (PNUD/RDH, 2003, p. 4).

No entanto, os REPT de 2010 e 2011 insistem na dificuldade de se cumprir as metas de uma educação de qualidade acessível a todos, já que o aprendizado formador de habilidades, valores e atitudes capazes de melhorar a vida individual e coletiva exige mudanças nos contextos sociais, econômicos, políticos e culturais. Sociedades mergulhadas em preconceitos, discriminações, perseguições sociais, 128 conflitos armados, violências diversas, guerras e crimes, entre outros, encontram muitos empecilhos ou até mesmo bloqueios intransponíveis que tornam totalmente impossível uma escolarização mais justa para todos. Isso porque o cotidiano de crianças, jovens e adultos é, muitas vezes, um caos. Daí a necessidade de discutir se os ambientes microssocial e macrossocial são adequados para a realização da justiça escolar.

Algo muito destacado nos REPT $(2010,2011)$ é a forma como a violência e a privação obstam o alcance das metas de uma educação justa para todos. A pobreza extrema, combinada com diversas de discriminações e exclusões, por exemplo, constitui uma forma de bloqueio permanente na vida das pessoas. Crianças e jovens que vivem em situação de guerra, fome, miserabilidade e crimes têm suas chances de aprendizado diminuídas. Se a escola justa é aquela que amplia o acesso, a permanência e a qualidade educacional, então esses casos apresentam obstáculos muitas vezes 
intransponíveis. Na verdade, no otimismo dos diagnósticos e das prescrições nota-se uma estratégia política dos organismos internacionais: trata-se de fazer parecer possível, ainda que todas as condições o neguem.

\section{Pobreza, exclusão, ausência de direitos e negação da justiça escolar}

Os REPT estão repletos do movimento entre possível e impossível, entre idealização e realidade negadora das possibilidades de mudança. Isso fica claro quando discutem a situação de crianças e jovens que vivem num entorno escolar e doméstico com muitas formas de intolerância e discriminação. Nesses momentos vê-se o quanto é difícil um aprendizado que garanta o desenvolvimento humano ${ }^{7}$ contínuo ao longo da vida. Educação, desenvolvimento humano e direitos humanos são eixos centrais das perspectivas abraçadas por esses dois grupos de documentos. Por isso eles são expressivamente distintos dos Relatórios do desenvolvimento mundial (Banco Mundial, 2015), em que a educação e o desenvolvimento não têm como norte a aposta numa perspectiva dos direitos sociais e humanos (Etchichury, 2015). No RDH de 2000 consta que "Investir na capacidade básica e garantir os direitos na lei são uma combinação poderosa para facultar aos pobres [...] sair da pobreza. Entre esses amplos conjuntos de direitos - civis, políticos, econômicos, sociais e culturais - há nexos importantes [...]" (PNUD/RDH, 2000b, p. 75).

Merece destaque o fato de que os elaboradores dos REPT têm trilhado um caminho aberto na segunda metade do século $\mathrm{XX},{ }^{8}$ o qual considera a pobreza extrema e as discriminações como empecilhos às condições de aprendizado.

\footnotetext{
7 O desenvolvimento humano é a viga mestra das prescrições dos RDH e dos REPT.

8 Este caminho foi aberto pela Declaração Universal dos Direitos Humanos de 1948 e seguiu com a Declaração dos Direitos da criança de 1959, a Declaração Mundial pela Educação para Todos de 1990 e a Declaração dos objetivos do milênio de 2000.
} 
É impossível chegar à justiça escolar se, antes disso, a miserabilidade e a discriminação excluem a criança da escola. A garantia de que todos possam estar na escola é a primeira condição para a execução de ações e procedimentos que levem a uma escolarização justa, garantidora da construção de um saber voltado para a formação de diversos tipos de conhecimento, valores, atitudes e habilidades. "Milhões de crianças ingressam na escola com suas capacidades de aprendizagem irremediavelmente deterioradas como resultado da má nutrição e [da] carência de micronutrientes" (Unesco/REPT, 2010, p. 54).

Prevalece a ideia de que a escolarização deve formar um conjunto de disposições, motivações, expectativas e perspectivas geradoras de subjetividades que valorizem os benefícios de uma escolarização, de fato, inclusiva e igualitária. Todavia, os formuladores dos REPT não restringem suas prescrições aos processos formativos de subjetividades, nos 130 diversos agentes envolvidos com a escolarização, capazes de favorecer o aprendizado. Insistem também na necessidade de construir condições objetivas (sociais, econômicas e políticas) que gerem um ambiente macrossocial e microssocial favorável a um aprendizado contínuo e duradouro.

Os REPT deixam evidente a associação entre marginalização e injustiça social e escolar. Grupos inteiros são marginalizados no que tange não só aos rendimentos, mas também ao aprendizado. Percebe-se no REPT de 2010, assim como em outros RDH (PNUD/RDH, 2004), que a marginalização econômica não pode se estender à área educacional. Ainda que marginalizado no mundo da renda, o indivíduo não pode estar marginalizado no mundo da escolarização e na vida social e política de modo geral. As condições de marginalização tendem a se espraiar e inviabilizar o acesso ao conhecimento, à aprendizagem e à escolarização. Os formuladores dos dois grupos de documentos ora analisados difundem, através de seus diagnósticos e prescrições, a ideia de que combater a injustiça escolar é uma forma de 
amenizar as injustiças sociais. "O tempo passado na escola é somente um dos aspectos da marginalização. No aproveitamento escolar também se dão diferenças muito marcantes que guardam relação com a situação socioeconômica" (Unesco/REPT, 2010, p. 11).

Ressalte-se que, não obstante as reflexões dos produtores dos RDH e dos REPT se pautarem no debate sobre privações relativas e absolutas, as privações relativas de renda geralmente se convertem, como afirma Sen (1978), em privações absolutas de capacidades (Romão, 1982). Daí a ênfase na educação como forma de superar, se bem que em parte, a marginalização social. A marginalização no conhecimento e na aprendizagem indica a profundidade das demais formas de exclusão. Todavia, os documentos em análise evidenciam enorme dificuldade de lidar com as desigualdades socioeconômicas e seus impactos sobre a injustiça escolar e seus desdobramentos. As prescrições acabam se situando em formas de combater a pobreza e a miserabilidade extremas que bloqueiam o desenvolvimento educacional e aprofundam as diversas formas de exclusão e marginalização.

Intolerâncias, desprezos e preconceitos vivenciados no universo escolar e fora dele formam também um ambiente altamente destrutivo à justiça escolar, segundo os produtores dos RDH de 2004, quando não há possibilidade de um processo de ensino-aprendizagem que desmonte, na escola e em seu entorno, tais condições de discriminação. Por isso, "o avanço da liberdade cultural deve ser um aspecto central do desenvolvimento humano e exige que vamos para lá das oportunidades sociais, políticas e econômicas, uma vez que por si sós não garantem liberdade cultural" (PNUD/ $\mathrm{RDH} / 2004$, p. 13). Desse modo, também no âmbito da escola "a liberdade cultural é violada pela falta de respeito ou de reconhecimento dos valores, instituições e modos de vida de grupos culturais e pela discriminação e desvantagem baseadas na identidade cultural" (PNUD/RDH/2004, p. 27). 
Observa-se nas discussões do RDH de 2004 - o qual trata mais diretamente da necessidade de considerar uma justiça diferencialista - uma crítica às instituições, de modo geral, e às escolares, em especial, que muitas vezes abraçam um "conservadorismo cultural" para combater a diversidade cultural. Ao fazê-lo, essas instituições tomam "posições antiliberdade [...] [para] bloquear a escolha de um modo de vida diferente que muitas pessoas podem desejar ter" (PNUD/ $\mathrm{RDH}, 2004$, p. 16). Isso seria inteiramente contrário ao processo de construção de uma escola mais justa, já que se alimenta de uma "exclusão do modo de vida" de grupos sociais e étnico-raciais inteiros (PNUD/RDH, 2004, p. 16).

Se, para ser justa, uma escola "deve mobilizar a justiça escolar como igualdade de tratamento, quer no acesso, quer no sucesso, quer na possibilidade de permanecer no sistema" (Estevão, 2016, p. 53), então pode-se dizer que no RDH de 2004 encontram-se vários elementos prescritivos 132 acerca da necessidade de os Estados, governos e sociedade civil se empenharem na geração de uma política educacional que potencialize um cotidiano escolar menos tensionado por preconceitos e discriminações de diversas naturezas.

\section{Considerações finais}

Demonstrou-se a grande relevância, na atualidade, de compreender a consequência desses enquadramentos teóricos analíticos, como a daqueles que têm produzido a noção de desenvolvimento humano assentado na ampliação de habilidades e capacidades ancoradas num dado modelo de educação. Faz-se necessário, ainda, decifrar a consequência de procurar soluções para as injustiças escolares tendo como base o modelo de educação escorado por um enquadramento analítico acerca de uma ideia de justiça social genérica que, supostamente, é possível aplicar nos dois hemisférios, em todos os continentes e contextos. Deriva daí, muitas vezes, a perda das especificidades dos 
contextos sócio-históricos e políticos que bloqueiam toda e qualquer possibilidade de avançar rumo a uma escola justa e a uma justiça escolar. Esses enquadramentos analíticos e teóricos, que não se assentam nas particularidades sóciohistóricas de cada região, continente ou país, articulados pelas ciências sociais e/ou por organizações internacionais, não dão relevo às especificidades bloqueadoras das possibilidades de se efetivarem, no âmbito microssocial e no macrossocial, ações favoráveis à abertura de caminhos por onde poderiam fluir processos educacionais, políticos, econômicos e sociais ancorados na efetivação da justiça e do direito.

O plano macrossocial estruturado sobre desigualdades e pobrezas extremas, fome, violências, guerras, discriminações étnico-raciais, carência de serviços públicos, entre outras situações, potencializa as dificuldades de ensino e de aprendizado. Em tais condições, a justiça escolar fica inteiramente impossibilitada, já que é minada pela negação da formação de ambientes favoráveis ao aprendizado. $\mathrm{E}$ isso se desdobra para o âmbito microssocial, conforme enfatiza a já citada Declaração mundial sobre educação para todos, de 1990. Estando numa esfera doméstica e comunitária afetada por miséria e violência, bem como em esferas sociais, econômicas e políticas mais amplas que exacerbam as desigualdades, a violência, as discriminações e a pobreza multidimensional, é óbvio que a criança tem diante de si muitos obstáculos. As injustiças sociais potencializam as injustiças escolares, tais como escolas precárias, encravadas em lugares violentos que impossibilitam as crianças de ter tranquilidade e paz para os estudos.

\section{Maria José de Rezende}

é doutora em Sociologia pela Universidade de São Paulo (USP), professora associada do Departamento de Ciências Sociais e membro do Programa de Pós-Graduação em Sociologia (Mestrado e Doutorado) da Universidade Estadual de Londrina (UEL). 


\section{Bibliografia}

BANCO MUNDIAL. 2015. Relatório mundial do desenvolvimento: mente, sociedade e comportamento. Washington, DC: 2015. Disponível em: http://www.worldbank.org. Acesso em: 12 fev. 2018.

BOLTANSKI, Luc. 2009. De la critique: précis de sociologie de l'émancipation. Paris: Gallimard.

BOLTANSKI, Luc; THÉVENOT, Laurent. 1991. De la justification: les économies de la grandeur. Paris: Gallimard.

BOLTANSKI, Luc; THÉVENOT, Laurent. 1999. A sociologia da capacidade crítica. Antropolítica, v. 23, n. 2, pp. 121-144.

CAMPOS, Luiz Augusto. 2016. Qual capacidade crítica? Relendo Luc Boltanski à luz de Margaret Archer. Revista Sociedade e Estado, v. 31, n. 3, pp. 719-740.

CELIKATES, Robin. 2012. O não reconhecimento sistemático e a prática da crítica. Novos Estudos, n. 93, pp. 29-42.

CONFERÊNCIA MUNDIAL SOBRE EDUCAÇÃO PARA TODOS. (1990). Declaração mundial sobre educação para todos: plano de ação para satisfazer as necessidades básicas de aprendizagem. Jomtien, Tailândia. Disponível em: https://uni.cf/2ITkWG9. Acesso em: 30 jan. 2018.

CORREAA, Diogo Silva; DIAS, Rodrigo Castro. 2016. Crítica e os momentos críticos: De la justification e a guinada pragmática na sociologia francesa. Mana, v. 22, n. 1, pp. 67-99.

DIONÍSIO, Bruno. 2010. O paradigma da escola eficaz entre a crítica e a apropriação social. Sociologia: Revista do Departamento de Sociologia da FLUP, v. XX, p. 305-316.

DUBET, François. 2004. O que é uma escola justa? Cadernos de Pesquisa, v. 34, n. 123, pp. 539-555.

DUBET, François. 2012. Los límites de la igualdad de oportunidades. Nueva Sociedad, n. 239, pp. 42-50.

ESTEVÃO, Carlos V. 2002. Justiça complexa e educação: uma reflexão sobre a dialectologia da justiça em educação. Revista Crítica de Ciências Sociais, n. 64, pp. 107-134.

ESTEVÃO, Carlos V. 2016. Justiça social e modelos de educação: para uma escola justa e de qualidade. Revista Diálogo Educacional, v. 16, n. 47, pp. 37-58. Disponível em: http:/ /bit.ly/2OLRhm9. Acesso em: 6 set. 2018.

ETCHICHURY, Horacio Javier. 2015. La mente, la probreza y el Banco Mundial. Revista Enfoques, n. 23, pp. 49-65.

FÓRUM MUNDIAL DE EDUCAÇÃO. 2000. Educação para Todos:

o compromisso de Dakar. Dakar, Senegal. Disponível em:

http:/ /bit.ly/2IRA1rS. Acesso em: 12 out. 2013. 
PNUD/RDH. 2000a. Síntese. Relatório do desenvolvimento humano. Disponível em: http://bit.ly/2ITHabf. Acesso em: 15 set. 2019. PNUD/RDH. 2000b. Relatório do desenvolvimento humano 2000: direitos humanos e desenvolvimento humano - pela liberdade e solidariedade. Disponível em: http://bit.ly/2nNiERL. Acesso em: 6 set. 2018. PNUD/RDH. 2003. Relatório do desenvolvimento humano: um pacto entre nações para eliminar a pobreza humana. Disponível em: http:/ / bit. ly/2oL8UaZ. Acesso em: 6 jan. 2018.

PNUD/RDH. 2004. Relatório do Desenvolvimento Humano: a liberdade cultural num mundo diversificado. Disponível em: http://bit.ly/2Mkrdgt. Acesso em: 6 jan. 2018.

RESENDE, José Manuel; DIONÍSIO, Bruno Miguel. 2005. Escola pública como "arena" política: contexto e ambivalências da socialização política escolar. Análise Social, v. 9, n. 176, pp. 661-680.

ROMÃO, Maurício E. C. 1982. Considerações sobre o conceito de pobreza. Revista Brasileira de Economia, v. 36, n. 4, pp. 355-379.

SEN, Amartya. 1978. Three notes on the concept of poverty. ILO Working Paper, n. 54, pp. 2-23.

SEN, Amartya. 2008. A desigualdade reexaminada. Rio de Janeiro: Record.

SEN, Amartya. 2010. Desenvolvimento como liberdade. São Paulo: Cia das Letras.

SEN, Amartya. 2011. A ideia de justiça. São Paulo: Cia da Letras.

UNESCO/REPT. 2010. Informe de seguimiento de la educación en el mundo: llegar a los marginados. Unesco. Disponível em: http://bit.ly/2ox9Qjn. Acesso em: 16 fev. 2018.

UNESCO/REPT. 2011. Informe de seguimiento de la educación en el mundo: una crisis encubierta: conflictos armados y educación. Unesco. Disponível em: http://bit.ly/2IRBdvn. Acesso em: 16 fev. 2018. 


\section{JUSTIÇA ESCOLAR E JUSTIÇA DIFERENCIALISTA NOS DOCUMENTOS ADOTADOS POR ÓRGÃOS DAS NAÇÕES UNIDAS (PNUD E UNESCO)}

\section{MARIA JOSÉ DE REZENDE}

Resumo: Alguns órgãos internacionais, como o Programa das Nações Unidas para o Desenvolvimento e a Organização das Nações Unidas para a Educação, a Ciência e a Cultura, têm desencadeado, no limiar do século XXI, diversas investidas para participar da formulação de modelos de educação que reiterem noções singulares de justiça social e inclusão escolar. Pretende-se alcançar tal inclusão por meio da democratização de um conhecimento que capacite os segmentos sociais diversos a participar satisfatoriamente no mundo social, político e econômico. Em circunstâncias sociais específicas - entre elas, dificuldade de diminuir as desigualdades sociais, étnicas e raciais; redução dos postos de trabalho e das expectativas de obtenção de emprego por parte de grupos sociais inteiros; desconfiança da eficácia da escola para gerar indivíduos habilitados tanto profissional quanto politicamente -, os formuladores desses documentos buscam modos de participar do debate político e acadêmico acerca de justiça social, justiça escolar e escola justa.

Palavras-chaves: Educação; Escola Justa; Justiça Social; Organismos Internacionais.

\section{SCHOOL JUSTICE AND DIFFERENTIAL JUSTICE IN DOCUMENTS ADOPTED BY UNITED NATIONS BODIES (UNDP AND UNESCO)}

Abstract: On the threshold of the $21^{\text {st }}$ century, some international organizations, such as the United Nations Development Programme and the United Nations Educational, Scientific and Cultural Organization, have launched a series of initiatives to participate in 
the formulation of educational models that reiterate singular notions of social justice and school inclusion. Such inclusion is intended to be achieved through the democratization of a knowledge that enables the various social segments to participate satisfactorily in the social, political and economic world. Under specific social circumstancessuch as difficulty in reducing social, ethnic and racial inequalities, decrease of jobs and employment expectations by entire social groups, mistrust on the school's effectiveness to generate both professionally and politically empowered individuals -, the formulators of these documents search ways to participate in the political and academic debate about social justice, school justice and fair school.

Keywords: Education; Fair School; Social Justice; International Organizations.

Recebido: 26/03/2019 Aprovado: 24/09/2019 